\title{
Review of Indicators for Localizing Environmental Goals at Sub National and Local Level in Nepal
}

\author{
Ek Raj Sigdel ${ }^{1, *}$, Martina Maria Keitsch ${ }^{2}$ \\ ${ }^{1}$ World Wildlife Found, Nepal \\ ${ }^{2}$ Norwegian University of Science and Technology, Trondheim, Norway \\ Corresponding Email: ekrajsigdel@gmail.com
}

\begin{abstract}
:
Nepal, as a member of the United Nations, is committed to achieve the global initiatives of Sustainable Development Agenda by 2030. Toward translating the commitment into action, Nepal has produced preliminary SDGs Report in 2015, even before the formal adoption of the 2030. Moreover, Voluntary National Review Report, Sustainable Development Goals, Status and Roadmap: 20162030, and Sustainable Development Goals 2016-2030 National (Preliminary) Report were developed. Further, Nepal has initiated mainstreaming the 2030 Agenda into national policies and plans. The 14th periodic plan, the national budget, and other sectoral plans have been closely aligned with the SDGs and the approach paper for 15th five-year plan is intended to achieve the SDG. The upcoming 15 th periodic plan will basically aim to support the government in achieving all the SDGs by 2030 and help Nepal emerge as a middleincome country by 2030. The indicators comprise of renewable energy for electricity and vehicles, injuries due to disaster (number), greenhouse gases, adaptation plans, trained man power, climate change educations, and climate smart villages and farming are identified as indicators under climate and energy goals. Similarly, under forest goals proportion of forest land, forest under community-based management (\% of total dense forest areas), protected area (including forest, in $\%$ of total land area), handover of forests to leasehold forest groups (000 hectare), wild tigers (number), rhino (number) etc are included. Likewise, conservation of lakes, wetlands, and ponds (number) and potentially dangerous lakes (\%) are included under fresh water goals. However, there was no scientific basis how the indicators were derived for the environmental goals. In this backdrop, a study in identifying site specific, measurable, time bound, relevant and attainable indicators was paramount. Based on the secondary literature review, stakeholder consultation at sub national and local level, the indicators were verified and suggested strategies that help localizing the environmental indicators at sub-national and local level in Nepal. The study was therefore centered on reviewing the environmental indicators and suggest appropriate strategies so that it helps expediting localization of SDG in Nepal.
\end{abstract}

Keywords: Sustainable Development Goals, Indicator

\section{Introduction}

The Constitution of Nepal (2015) guarantees inclusive socio-economic and political development, the building of an egalitarian and pluralistic society and the elimination of all forms of discrimination. This Constitution is the main guiding document for all new policies, plans ad programmes, and other interventions to implement the aspiration of the SDGs. The government has already started to mainstream the SDGs into national planning and budgeting systems. The Fourteenth Plan (2016/172018/19) which has in-built result framework, internalises key aspects of SDGs through systematic integration of SDGs in the periodic plans needs rigorous works which the country has already initiated. In addition, the annual programmes and budgets of 2016/17 and 2017/18 of Nepal have been aligned with the SDGs by introducing SDGs coding to each and every programme.
The main indicators related to environmental SDGs are proportion of population with access to electricity, primary reliance on clean fuels and technology, households using solid fuel as primary source of energy for cooking, electric consumption, renewable energy share in the total final energy consumption, electric vehicles in public transport system. Similarly, local adaptation plan preparation (number of wards), community level adaptation plan and its implementation, climate smart villages, climate smart farming, proportion of schools covered by climate change education and number of trained persons in climate change mitigation.

And remaining indicators are forest area as a proportion of total land area, conservation of lakes, wetlands, and ponds (number), protected area (including forest, in percent of total land area), progress toward sustainable forest management, forestation in public and private lands (Ropani/year), additional plantation, proportion of land 
that is degraded over total land area, conservation of rivulet and river banks through bio-engineering.

The baseline report on SDGs has set 428 indicators under 16 various goals that are concerned with Nepal; however, the discussion is there that it will be tough to monitor and keep proper database of each indicator that demands reviewing the indicators. There are 159 targets and 471 indicators for Nepal. It includes a total of 90 environmental indicators of which 39 are global and 51 are added by Nepal. The detailed of the environmental goals and indicators are depicted in table 1.

Table 1: Environmental SDGs, global indicators and additional indicators made by Nepal

\begin{tabular}{|l|l|l|l|}
\hline SDG-Goal & Global indicators & Nepal added & Total \\
\hline 6 & 11 & 14 & 25 \\
\hline 7 & 6 & 9 & 15 \\
\hline 13 & 8 & 11 & 19 \\
\hline 15 & 14 & 17 & 31 \\
\hline Total & 39 & 51 & 90 \\
\hline
\end{tabular}

In this backdrop, a study in identifying site specific, measurable, time bound, relevant and attainable indicators were required. Based on the secondary review, stakeholder consultation at sub national and local level, the indicators were further verified and enlisted indicators and priority activities that help localizing the environmental indicators at sub-national and local level in Nepal.

\section{Methodology}

SDGs related documents in order to identify need and gaps for integrating SDGs, mainly localization of SDGs, capacity development, renewable energy, climate change and bio-diversity in planning, monitoring and reporting procedures of the government were reviewed.

With the objective of localizing Environmental SDGs, WWF organized stakeholder workshops in selected four municipalities and two state government level through province based civil society organizations. Workshops were conducted in Laligurans and Myanglung Rural Municipalities of State Number One and Khadachakra and Lakebeshi Municipalities of Karnali Province. Similarly, one workshop in each Province One and Karnali were conducted. Environment related Sustainable Development Goals $(6,7,13 \& 15)$ and its indicators were shared with a total of 239 participants including State Legislative Parliamentary Members, Mayors, Deputy Mayors, Ward Chairs among others. Of the total
Participants, 78\% were male. Similarly, the Workshops witnessed participation of $21 \%, 17 \%$, and $62 \%$ Janjati, Dalit and other categories respectively.

\section{Need and Gaps for localizing Environmental SDG indicators}

The SDGs 7 targets include achieving, by 2030, universal access to affordable, reliable and modern energy services, increasing substantially the share of renewable energy in the global energy mix and doubling the global rate improvement in energy efficiency.

In Nepal nearly three-fourth (74.7 percent) of households are using solid fuels and the primary source of energy for cooking, while one-fifth (18 percent) are using LPG for cooking. Usage of LPG has increased rapidly however, household's heavy reliance on traditional energy sources (solid fuels) seems unchanged. While nearly three-fourth (74 percent) of the households have access to electricity in their dwellings, the actual supply of electricity is far below the demand [1]. For overcome of this condition and achievement of SDGs targets, the passion of local government will necessary and make ready to endorse the clean energy concept through local development intervention.

The proposed specific targets of Nepal for SDG 13 include making half the existing $\mathrm{CO}_{2}$ emission level including form transportation, industrial, and commercial sectors. Consumption of ozone depleting substance is targeted to reduce to one third of the existing level. Climate change adaptation plan is proposed for 120 Village Councils and 750 communities by 2030 . In the meantime, climate smart villages are proposed to increase from zero to 170 and climate smart farming to 500 units from zero at present. Almost all the schools will be covered by climate change education and the number of trained persons (local planners) for climate change planning would reach 3 thousand [2]. Lack of capability and resources of local government, additional support and resource will be required for achievement of these targets.

SDG 15 related to protect, restore and promote sustainable use of terrestrial ecosystems, sustainably manage forests combat desertification, and halt and reverse land degradation and halt biodiversity loss. The 2030 target is to maintain conservation area at 23.3 of the total land area, increase forest under community management from 39 percent to 42 percent of the forest area, halt forest loss and degradation, increase mountain ecosystem covered by the protected area to 70 percent in 2030 from 68 percent in 2015, and undertake additional plantation of 5000 
hectares each year [3]. It is also one important target for environmental protection and sustainable development. The national targets are clear and it will be achieved only when local development initiatives will be counted and cumulate to national data base. One of the important gaps is measuring local level SDGs's progress framework and mechanism of integration to national level progress.

\section{$4 \quad$ Main Findings}

Laligurans and Myanglung Municipalities of Province Number One identified about 20 energy, water, forest and climate change related issue. The issues that needs indicators were as follows:

○ Drying water resources

○ Biodiversity conservation specially Tinjure Milke Jaljale (TMJ) area

- Need of alternative energy instead of fossil oil, and fuel wood

- Massive use of pesticides in agriculture farming and vegetable

○ Climate induced disaster (Drought, heavy rain,)

○ Lack of climate smart technology

○ Unplanned infrastructure construction

- Unmanaged solid waste and garbage in recently growing urban area

Similarly, Khadachakra and Lakebeshi Municipalities of Province Number six has prioritized environmental activities. The priority activities were as follows:

- As most of the wards of the municipality has not been electrified, electrification must be encouraged. (Amongst the 9 wards in the Khandachakra municipality, only 3 wards are electrified and in Lekbeshi municipality, only ward 6 has been electrified).

○ Promotion of non-smoking oven and biogas.

- Increase forest cover in both municipalities.

- Increase the density of private and community forest

- Make availability of safe drinking water and scientific garbage management.

- Increase the number of lakes and ponds

○ Promotion bio-engineering technology for making rural road sustainable
- Only earthquake resistant and environment-friendly design for infrastructure are to be approved

- Climate favorable planning is encouraged in all the wards of the municipality

- Adoption of climate favorable agriculture system in the municipality.

- Include the effects of climate change and the solution to it in the local curriculum.

Based on the field and province level workshops, it was revealed that the environmental issues were different in different locations. To deal with the issues, only about two dozen indicators would be enough. Therefore, nationally proposed long lists of indicators need to be reviewed and make more flexible so that they can be aligned with site specific issues and it helps expediting the environmental SDG localization process in Nepal. Capacity of Province level government should be enhanced so that they can play role of coordination specially for the implementation of common issues and indicators at local level. Being the first of this kind of localization workshops at Province and Local level, much discussions were centered at goal and target level and limited time was spared to discuss at indicator levels. Therefore, more discussions should be carried out in indicator level in the ensuing years. Further, local government lack data and resources for tracking and monitoring of SDGs. Data collection and monitoring mechanism should be developed and clarified during planning phase in the years to come.

\section{Challenges, Learning and Recommendation}

- As the concept of SDG as such was quite new for the participants, it was very challenging to sensitize them about the national target and indicators of all 17 SDGs within the limited time framework

- Lack of baseline data and relevant information on the indicators made difficult to define target and monitoring framework for the SDGs.

- Some indicators are identified by two municipalities which should be implemented as a common indicator for both municipalities and need joint efforts for more than the two local governments. Coordination is needed from state level government in order to address the common issues. SDG localization should consider role of province as they have mandated to coordinate local government units. 
- The function and structure of the state and local bodies are not very clear on various environmental issues.

- It seems a lot work yet to be done that demands heavy resources and follow up. WWF's role in achieving SDG $6,7,13$ and 15 is found very important. The existing event-based activities has been found instrumental to understand the localization situation and find scope of work. It is desirable to work with partner organization in a long run basis. Work through NGO with long term partnership modality instead of event-based activity

\section{Conclusion}

In connection with SDG localization, it was necessary to review relevancy of the environmental indicators. In connection with reviewing the SDG, the given indicators were reviewed through organizing workshops at local and state level in Nepal. Based on reviewing literatures and stakeholder workshop outcomes, the relevant environmental indicators were identified. Some SDG targets are less relevant for Nepal while new and additional targets would be necessary to address country specific challenges. Therefore, it is important to review the indicators as soon as possible.

\section{Acknowledgement}

The authors are grateful to local government units who shared their policies and plans and contributed time and knowledges. Thanks also due to WWF Nepal for supporting the study in the selected state and local government units.

\section{References}

[1] NPC, 2017: Nepal's Sustainable Development Goals, Baseline Report June 2017, NPC

[2] NPC, 2016-2030: Sustainable Development Goals Status and Roadmap: 2016-2030, NPC

[3] NPC, 2016-2030: Sustainable Development Goals Status and Roadmap: 2016-2030, NPC 